\title{
Health Workers' Commitment in Delta State: Influence of Personality and Workplace Experiences
}

\author{
1Adejuwon, G.A. (Ph.D.) \\ ${ }^{2}$ Aderogba, $A$. \\ ${ }^{3}$ Adekeye, O.A. (Ph.D.)

\begin{abstract}
1,2 Department of Psychology, Faculty of the Social Sciences, University of Ibadan, Ibadan, Oyo State, Nigeria ${ }^{3}$ Department of Psychology, College of Leadership Development Studies, School of Human Resources Development, Covenant University, Ota, Ogun State, Nigeria
\end{abstract}

\section{Doi:10.5901/mjss.2015.v6n4s2p258}

\begin{abstract}
Aim: Health workers' commitment is very important in the effective discharge of their duties but this may be compromised when challenged by workplace experiences. Research is therefore required to provide data base to inform policy decision on health workers' commitment to their work. This research therefore investigated personality (emotional intelligence and fortitude) and workplace experiences (job-characteristics and perceived alternative employment opportunities) as predictors of commitment among health workers. Method: The study utilized cross - sectional design. The participants were two hundred and twenty-three (223), randomly selected from Federal Medical Center, Delta State- 90(40.4\%) males and 133(59.6\%) females with the mean age of 34.3 and standard deviation of 8.07. The participants completed a structured questionnaire that measures the dependent and independent variables of the study. Inferential statistics were used to test the hypotheses stated. Result: The independent variables significantly and jointly predicted $12 \%$ of the variance in career commitment among the health workers. Specifically, emotional intelligence independently influenced career commitment. Job status and year of experience jointly and significantly interacted to influence career commitment. However, only job status had significant main influence of on career commitment. Married respondents reported higher level of career commitment than those who were single. Conclusion: Emotional intelligence, job status and being married were associated with the career commitment of the health workers in this study. It is recommended that policy makers should incorporate these factors into capacity building programmes to enhance health workers' commitment.
\end{abstract}

Keywords: Health workers' Commitment, Personality, Workplace Experiences.

\section{Introduction}

Career commitment which can be regarded as a form of work commitment is a term which may be used to describe workers' attitude to their work. Career commitment is characterised by development of personal career goals, attachment to, involvement and identification with the goals. employee is said to have career commitment when opportunities are provided for the development, of career goals, In the world of work today, career seem to provide occupational meaning and ensures continuity even when the organizations are unable to provide job security. Most employees will stay on their jobs as long as there is career path that can be built. Career commitment is most especially important to health care workers who have to care for the sick with various types of ailment. Health workers may be dependable to the extent to which they are committed to their work.

This study is based on Adams Stacy equity theory of motivation which states that when employees perceive what they get from a job situation (outcomes) in relation to what they put-in (inputs), they compare their outcome-input ratio with the outcome-input ratio of relevant others. If employees perceive the ratio to be equal to that of the relevant others with whom they compare themselves, a state of equity is said to exist; they perceive their situation as fair and that justice prevails which make them more committed to their career.

Nowadays, hospitals are confronted with challenges such as scarce resources than ever before. Health workers, play an important role in the provision, accessibility, quality and cost of healthcare. Issues on career commitment for health workers are of paramount importance for administrators and managers in health organizations due to the crucial role they have to play. Research has generally found that satisfied employees are more productive and committed to their career, whereas dissatisfied ones experience absenteeism, grievances and all forms of counterproductive behavior 
(Alarape and Akindipe, 2004). Many health workers discover that the tasks they are expected to perform are more difficult and challenging than they anticipated from their experience as workers (Salanick, et al 2003). As a result of this, employees question their career choice after they start their job and long for better opportunities while still in their current job (Holton, 2005).

Emotional intelligence (EI), is the ability to understand self and others' feelings and to utilize the knowledge towards enhancing performance in all ramifications. Salovey and Mayer (2001) argued that there are three sets of conceptually related mental processes to emotional intelligence - appraising and expressing emotions in the self and others, regulating emotion in the self and others, and using emotions in adaptive ways - involving emotional information.

Appraising and expressing emotions in the self and others is the degree to which people are aware of their emotions (appraisal) and the degree to which the latter are verbally and non-verbally being expressed. Regulating emotion in the self and others involves how people manage (monitor, evaluate, and adjust to changing moods) their emotions as well as in their ability to regulate and alter the affective reactions of others (Salovey and Mayer, 2001).

Using emotions in adaptive ways involve the ability of individuals to use their emotion either functional or dysfunctional ways. Workers who are able to understand their own emotions and that of others could be essential in their performance in the course career endeavours. Hence, the emotional intelligence of health workers could play a vital role in influencing their career commitment. Carmeli (2003) examined the relationship between emotional intelligence and work attitudes, behaviour and outcomes revealed that emotionally intelligent senior managers develop high commitment towards their career. However, emotional intelligence was statistically unrelated to job involvement. Emotional intelligence enables people to control this stress effectively and prevent its negative effect on one's attitude towards his/her career (Carmeli, 2003).

Perceived alternative employment opportunities (PAEO) refers to an individual's perception of the availability of alternative jobs in the organization's environment (Price \& Mueller, 2006), PAEO is another factor that has been seen to influence employee's commitment in the course of their career (Hulin et. al, 2002; Steel \& Griffeth, 2003). Employees may consider alternative job opportunities when the expected conditions of employment are not being met by the employer. In addition to the market condition, educational background may affect the perception. Mor Barak et al (2001) investigated that workforce with higher educational background perceived more employment opportunities. Higher educated workforce may consider their qualification as a competitive advantage over less educated workforce by having more choices of alternative positions.

Many researchers have indicated that job characteristics constitute factors have strong influence on employees' work outcome. The job characteristics model by Hackman and Oldman (1975) proposed that job design have implications for meaningfulness of the work performed, knowledge of the results of the work performed and responsibility for the work outcomes. All these have a significant influence on job commitment. Furthermore, job characteristics were found to have more impact on employees' job behaviour when compared with other predictors such as leadership (Yagil,2002); influence on participants' commitment (Schneider, 2003. Sanker and Wee,2005). Higher level of job satisfaction was associated with employees' higher job commitment (Bhuian and Menguc, 2002).

Fortitude as a construct could be considered as the ability of an individual to derive strength from self- appraisal, the family and support from others in order to manage stressful events and maintain positive wellbeing. According to Pretorious, (2007) our countless experiences with the world enables us to develop general beliefs about ourselves and our world. Peoples' evaluation of themselves, their support resources and their family and their environment influence their emotions and behaviour as they interact with the environment. Antonovsky (2002) suggested that people who perceive themselves, their abilities, support resources and their family environment negatively will have serious doubts about their ability to cope effectively with stressful life situations. Consequently, such people are prone to giving in to possible negative psychological effects of stressors. However, those who perceive themselves, their support and their environment positively will have a greater belief in their ability to deal with stressful life situations. The Health care profession is one of the most identified stressful professions. Thus there exists the need to understand how fortitude influences health workers' commitment. Fortitude as a construct offers a direction both for research as well as intervention. Developing an attitude of fortitude within the organisation can ensure that individuals possess the mental and emotional strength to overcome obstacles to performance and successfully achieve the task in hand (Pretorius \& Diedricks, 2004).

\section{Objectives of the Study}

The importance of commitment to duty among health workers cannot be overemphasised as this has implications for the discharge of their duties and the wellbeing of their clients. Some of the factors associated with career commitment among 
health workers have been identified in the literature reviewed. Therefore the main objective of this study is to examine the influence of personality (emotional intelligence and fortitude) and workplace experiences (job-characteristics and perceived alternative employment opportunities) on the commitment of health workers in Nigeria. Specifically, the study will:

1) Examine the independent and joint influence of fortitude, emotional intelligence, job characteristics and perceived alternative employment opportunities on the career commitment of the selected health workers.

2) Investigate the influence of job status and workplace experiences on the career commitment of the health workers.

3) Examine the influence of demographic factors such as marital status, sex, and age on the career commitment of the health workers.

\section{Hypotheses}

1. Fortitude, emotional intelligence, job characteristics and perceived alternative employment opportunities will jointly and independently significantly influence career commitment of health workers

2. Job status and experience will have main and interaction influence on career commitment of the health workers.

3. There would be significant influence of marital status on career commitment among health workers.

4. Male health workers will significantly be higher in career commitment than their female counterparts.

5. Younger health workers will significantly be higher in career commitment than their older counterparts.

\section{Method}

\subsection{Research Design}

The research design of this study is a cross sectional survey in which there is no active manipulation of independent variables, (which are emotional intelligence, job-characteristics, fortitude and perceived alternative employment opportunities). Demographic variables of the participants include: sex, educational qualification, marital status, tenure, rank and age form the demography variables.

Study population participants for this study are the health workers from Federal Medical Center in Delta State. Approval to use the medical centre for the study was given after the introductory letter was considered by the appropriate panel. Two hundred and sixty (260) participants were randomly selected for the study and individual voluntary consent for participation was obtained by the researchers. Consequently, a total of 260 questionnaires were distributed. At the end, $21(8.08 \%)$ were not returned, $223(85.77 \%)$ were retrieved, out of which $16(6.15 \%)$ were not correctly filled and then discarded. Therefore 223 questionnaires were used for the study giving a response of $85.77 \%$.

\subsection{Research Instrument}

The perceived alternative employment opportunities (PAEO) scale contained six items and was adapted from Mowday et al (1984). The scale showed good reliability $(a=.76)$ and uni-dimensionality (single factor in the factor analysis). It is a self-reported questionnaire which uses Likert scale responses to indicate degree of perceived availability of job. Responses on the questionnaires are on a Likert scale with possible responses ranging from 5 (strongly agree) to 1 (strongly disagree). A norm score of $5-15$ indicates low PAEO, while, a norm score of 16-25 indicates higher level of PAEO. The scale has a test -reliability coefficient of 0 . I1, the researcher recorded a mean of 76.57, variance of 105.19 and standard deviation of 10.256 . Validity of the tool was established using Cronbach test and alpha reliability co-efficient of $0.877(\mathrm{~N}=20)$ was obtained by the researcher.

The emotional intelligence scale used consists of sixteen items rated on a 5-point scale ranging from strongly Agree (5) to strongly disagree (1). It was developed by Wong and Law, (2002). The Wong and Law Emotional Scale (WLEIS) consists of four dimensions that are consistent with Salovey and Meyer's (2001) definition of El. The Self Emotion Appraisal (SEA) dimension assesses an individual's perceived ability to understand their emotions. The others' Emotion Appraisal (OEA) dimension assesses a person's tendency to be able to perceive other peoples' emotions. The use of Emotion (UOE) dimension concerns the self perceived ability to motivate oneself to enhance performance. The Regulation of Emotion (ROE) dimension has to do with one's perceived ability to regulate his/her emotions. Wong et al (2002) reported that the reliability coefficient of the four dimensions ranges from 0.79-0.81 using them to measure a single construct. Wong et al (2002) reported its Cronbach alpha to be 0.86 . A norm score of $16-48$ indicates low level of 
Emotional Intelligence, while, 49-80 indicates higher low level of Emotional Intelligence.

The Fortitude Questionnaire, (FORQ: Pretorious, 2004) instrument was designed to measure the strength to manage stress and stay well. It consists of 20 items that uses a five-point scale ranging from 5 "strongly agree to 1 "strongly disagree". These twenty items measure three domains, namely self appraisals, family appraisals and support appraisals. The sum of the three domains represents fortitude. In the initial validation study, the author reported reliability coefficients ranging from 0.74 to 0.85 . Heyns, Venter, Esterhuyse, Bam, and Odendaal (2003) reported reliability coefficients of 0.86 for an Afrikaans sample and 0.88 for an English sample. A norm score of 20-60 o the scale indicates a low level of fortitude, while, a score of 61-100 indicates a high level of fortitude.

Job Characteristics measure was adapted from Hackman and Oldham (1975). The Job-Characteristics scale was assessed with five subscales: skill variety, task identity, task significance, autonomy and feedback. All items were rated on seven-points Likert scale, ranging from 7 "very agree to 1 "very disagree". To determine the score of this scale, ratings within each scale are summed and divided by the total number of items in that particular scale. The overall internal consistency reliability for the Job Characteristics scale was 0.76 . A raw score norm of 11-14 on the scale indicates low favourable job characteristics, while 45-77 on the scale indicates high favourable job characteristics.

The Career commitment scale developed by Blau, (2003) comprised of 20 items. Each item reflects a facet of career commitment and it is measured on 5 point Likert format scale ranging from " 5 (strongly agree) to " 1 (strongly disagree)". The scale was originally developed for the purposes of measuring level of commitment to one's career path. The internal consistencies of the measure were reported to be .84 and .83 on insurance and newspaper samples, respectively. A norm score of 17 - 45 on the scale indicates a low level of career commitment, while, a score of $46-100$ indicates a high level of career commitment.

The Statistical Package for Social Sciences (SPSS 17) was used for the data analysis. Socio - demographic details of the respondents were analyzed using descriptive statistical technique such as frequency counts and percentages. Hypotheses one was analyzed using Multiple Regression Analysis, hypotheses two was analyzed using One-Way ANOVA and hypothesis three was analyzed using t-test for independent sample.

\section{Results}

\subsection{Sociodemographic Characteristics of Participants}

The age of the participants range from 16 to 53 years with mean of 34.3 and SD of 8.07 . The gender categorization shows that there were $90(40.4 \%)$ male and $133(59.6 \%)$ female participants. A furthermore breakdown of their marital status shows that 91 (40.8\%) single, $128(57.4 \%)$ married and 4 (1.8\%) widow. Furthermore, the educational qualification shows that $29(13 \%)$ participants have senior secondary school certificate, $46(20.6 \%)$ participants possessed OND/NCE/RNM/LAB SCl, 123 (55.2\%\%) participants have HND/Bachelors, while 11 (4.9\%) have Master's degree. The breakdown also reveals the participants Job Status, based on the position indicated by the participants, they were dichotomized into those whose work relate to administration or clerical(e.g account officer, clerk, admin officer etc) and health related responsibilities (for example, nurses, doctors, midwifes, dentist etc.). 82 (36.8\%) are within the administration related duty while, 141(63.2\%) within the health related duty.

\subsection{The correlation matrix of all the variables of the study}

Table 1: Showing correlation Matrix of all the Variables of the Study.

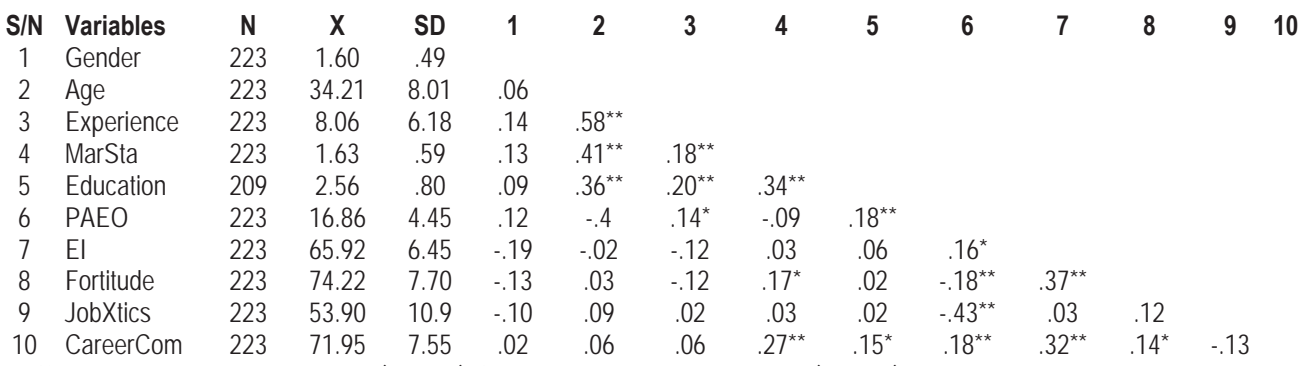


Table1 indicates that marital status was significantly positively correlated with career commitment $(r=0.27, P<0.01)$. Education also correlated significantly with career commitment $(r=0.15, P<0.05)$. Perceived alternative employment opportunities correlated significant positively with career commitment $(\mathrm{r}=0.18, \mathrm{P}<0.01)$; emotional intelligence correlated positively with career commitment $(r=0.32, P<0.01)$. Finally from the correlation table, the result shows that fortitude also correlated positively significantly with career commitment $(r=0.14, P<0.05)$.

5.3 Fortitude, Emotional Intelligence (EI), Job Characteristics and Perceived Alternative Employment Opportunities (PAEO) as predictors of Career Commitment of health workers.

Table 2: Showing summary of Multiple Regression Analysis showing Fortitude, Emotional Intelligence, Job Characteristics and Perceived Alternative Employment Opportunities will jointly and independently influence significantly, Career Commitment of Participants

$\begin{array}{lccccccc}\text { Variables } & \mathrm{B} & \mathrm{T} & \mathrm{P} & \mathrm{F} & \mathrm{R}^{2} & \mathrm{R} & P \\ \text { PAEO } & .17 & 1.40 & >.05 & 8.10 & .129 & .360 & \\ \text { El } & .331 & 4.01 & <.05 & & & & <.01 \\ \text { Fortitude } & .06 & .87 & >.05 & & & & \\ \text { Job Xtics } & -.07 & -1.41 & >.05 & & & & \end{array}$

The result in table 2 indicates that fortitude, emotional intelligence, job characteristics and perceived alternative employment opportunities significantly and jointly influence career commitment among health workers $F(4,218)=8.10$, $P<0.01$. Emotional intelligence $(\beta=0.33 ; t=4.01 ; P<.05)$ independently influenced career commitment. However, fortitude $(\beta=0.06 ; \mathrm{t}=0.87 ; P>.05)$, PAEO $(\beta=0.17 ; \mathrm{t}=1.40 ; P>.05)$, and Job Characteristics $(\beta=-.07 ; \mathrm{t}=-1.41 ; \mathrm{P}>0.05)$ did not significantly and independently influence career commitment.

\subsection{Main and interaction effect job status and years of experience on career commitment of the health workers}

Table 3: $2 \times 2$ ANOVA showing the main and interaction effect of Job Status and Years of experience on Career Commitment of Health workers

$\begin{array}{lccccc}\text { Variables } & \text { SS } & \text { Df } & \text { MS } & \text { F } & \text { P } \\ \text { Job status } & 364.42 & 1 & 364.42 & & \\ \text { Year of Experience } & 10.11 & 1 & 10.11 & 6.61 & <.05 \\ \text { Job Status x Exp. } & 357.95 & 1 & 357.95 & .18 & >05 \\ \text { Error } & 12082.76 & 219 & 55.17 & 6.49 & <.05 \\ \text { Total } & 1166958.00 & 223 & & & \end{array}$

The result in table 3 shows that there was significant main influence of job position on career commitment among health workers $F(1,223)=6.61 ; P<0.05$. The result also shows that job status and year of experience had significant interaction effect on career commitment $F(2,223)=6.49, P<0.05$. However, years of experience did not have main effect on career commitment $F(2,223)=0.18 ; P>05$.

\subsection{Influence of marital status on career commitment among health workers}

Table 4: One-Way ANOVA Showing the Influence of Marital Status on Career Commitment.

\begin{tabular}{|c|c|c|c|c|c|c|}
\hline Source & & SS & df & MS & $\mathrm{F}$ & $P$ \\
\hline $\begin{array}{l}\text { Between groups } \\
\text { Total }\end{array}$ & Within groups & $\begin{array}{c}1142.881151 .47 \\
12653.35\end{array}$ & $\begin{array}{l}2220 \\
222\end{array}$ & $\begin{array}{c}571.441 \\
52.32\end{array}$ & 10.92 & $<.01$ \\
\hline
\end{tabular}

The result in table 4 shows that there was significant influence of marital status on career commitment among health workers $F(2,222)=10.92 ; P<0.01$. Further analysis of this result using post hoc analysis is shown in Table 5 . 
Table 5: Least Significant Difference (LSD) Showing Marital Status on Career Commitment among Health Workers.

$\begin{array}{lcccccc}\text { Groups } & \mathrm{N} & \bar{X} \text { (Mean) } & \text { SD } & 1 & 2 & 3 \\ \text { Single } & 91 & 69.22 & 6.31 & - & & \\ \text { Married } & 128 & 73.82 & 7.90 & -4.60^{*} & - & - \\ \text { Widowed } & 4 & 74.00 & .00 & -4.78 & -18 & \\ \text { Total } & 223 & 71.95 & 7.55 & & & \end{array}$

*The mean difference is significant at the 0.05 level

The result in table 5 shows that married (Mean $=73.82$ ) respondents reported higher level of career commitment than those who were single (Mean $=69.22)$.

\subsection{Male and Female health workers on career commitment}

Table 6: Summary of t-test comparing Male and Female Respondents on Career Commitment.

$\begin{array}{lcccccc}\text { Gender } & \text { N } & \text { Mean } & \text { SD } & \text { T } & \text { DF } & P \\ \text { Male } & 90 & 71.77 & 8.13 & -.29 & 221 & >.05 \\ \text { Female } & 133 & 72.07 & 7.16 & & & \end{array}$

The result of the t-test shown in table 6 reveals that there was no significant difference between male and female health workers on career commitment $(\mathrm{t}=-.29, \mathrm{df}=221, \mathrm{P}>0.05)$.

\subsection{Young and old Health workers on career commitment}

Table 7: Summary of t test comparing Younger and Older Respondents on Career Commitment.

$\begin{array}{lcccccc}\text { Age } & \mathrm{N} & \mathrm{X} & \mathrm{SD} & \mathrm{T} & \mathrm{DF} & \mathrm{P} \\ \text { Younger } & 118 & 72.71 & 7.46 & 1.12 & 203 & >.05 \\ \text { Older } & 87 & 71.45 & 7.48 & & & \end{array}$

The result of the t-test shown in table 7 reveals that there was no significant difference between younger and older health workers on career commitment $(t=1.12, d f=203, P>0.05)$.

\subsection{Dimensions of Fortitude as joint and independent predictor of Career Commitment of Participants}

Table 8: Multiple Regression Showing Dimensions of Fortitude as joint and independent predictor of Career Commitment of Participants

$\begin{array}{lccccccc}\text { Variables } & \beta & \mathrm{T} & \mathrm{P} & \mathrm{F} & \mathrm{R}^{2} & \mathrm{R} & P \\ \text { Self Appraisal } & .013 & .112 & >.05 & & & & \\ \text { Family Appraisal } & .013 & .159 & >.05 & 2.04 & .024 & .216 & >.05 \\ \text { Support Appraisal } & .013 & -.112 & >.05 & & & & \end{array}$

The result in table 8 indicates that Self-Appraisal, Family Appraisal, and Support Appraisal did not significantly jointly and independently predict career commitment among health workers $F(3,228)=2.04, P>.05)$.

\subsection{Dimensions of Emotional Intelligence as predictors Career Commitment}

Table 9: Summary of Multiple Regression Analysis showing Sub scales of Emotional Intelligence as joint and independent predictors Career Commitment of Participants

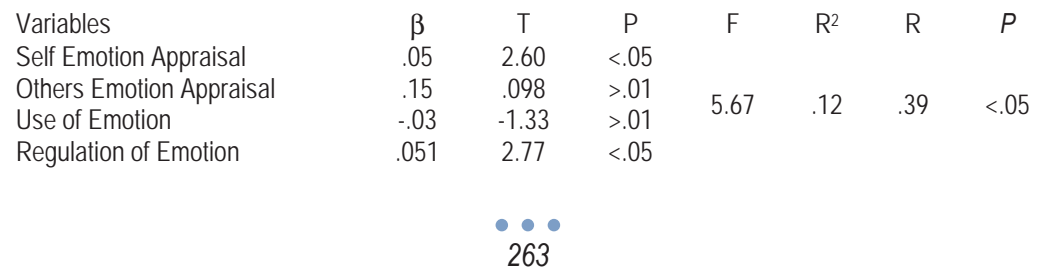


The result in table 9 indicates that Self Emotional Appraisal, Others Emotional Appraisal, Use of Emotion, and Regulation of Emotion significantly and jointly predict career commitment among health workers $F(4,228)=.12, P<.05)$. Selfemotional appraisal significantly and independently influenced career commitment $(\beta=.05 ; t=2.60 ; P<.05)$; Regulation of Emotion significantly independently influenced career commitment $(\beta=.051 ; t=2.77 ; P<.05)$. Emotional appraisal $(\beta=$ $.15 ; t=.098 ; P>.01)$, and Use of Emotion $(\beta=-.03 ; t=-1.33 ; P>.01)$, did not significantly influenced career commitment.

\subsection{Dimensions of Job Characteristics as Predictors of Career Commitment}

Table 10: Summary of Multiple Regression Analysis showing Sub scales of Job Characteristics as joint and independent predictors Career Commitment of Participants

$\begin{array}{lccccccc}\text { Variables } & \beta & \mathrm{T} & \mathrm{P} & \mathrm{F} & \mathrm{R} 2 & \mathrm{R} & P \\ \text { Skill Variety } & .002 & .144 & >.05 & & & & \\ \text { Task Identity } & -.026 & -.175 & >.05 & & & & \\ \text { Task Significance } & -.027 & -1.43 & >.05 & 2.09 & .08 & .28 & >.05 \\ \text { Autonomy } & .021 & 1.56 & >.05 & & & & \\ \text { Feedback } & .07 & .526 & >.05 & & & & \end{array}$

The result in table10 indicates that Skill variety, Task identity, Task significance, Autonomy and Feedback did not independently significantly and jointly predict career commitment among health workers $F(5,228)=2.09, P>.05)$.

\section{Discussion}

The findings in this study show that the independent variables jointly predicted career commitment of health workers. However, only emotional intelligence significantly predicted career commitment independently. Specifically, self-emotional appraisal and regulation of emotion dimensions of Emotional intelligence significantly and independently influenced career commitment. This outcome was in line with the work of Carmeli (2003) which revealed that emotionally intelligent senior managers develop high commitment toward their career. The reason for this finding is that emotionally intelligent workers could display cooperation, creativity and good interpersonal relations. They can also perceive, express and regulate emotions which could affect their attitude toward their colleagues, bosses, jobs and their commitment to their organizations. Goleman (2003) in his Mixed Models of Emotional Intelligence also stated that when workers understand their emotion and that of others, they are more likely to be more commitment to their career path by being productive and cooperative. Fortitude, emotional intelligence, job characteristics and perceived alternative employment opportunities were found to jointly predict career commitment among the health workers in this study. This is in line with Equity Theory proposed by Adams which states that the nature of equity employees receive from the workplace significantly affects their involvement in practices in the workplace and their overall satisfaction with their career path or choice. Perceived alternative employment opportunities were not found to be independent predictors of career commitment in this study.

Steel and Griffeth (2003) and Griffeth et al. (2003) reported weaker findings for the effect of perceived opportunities but slightly stronger results for the effect of intention to search on leaving which is in support of the finding that perceived alternative opportunities do not independently influence career commitment.

Although, both job status and years of experience had a significant interaction effect on career commitment, only job status was found to have significant main effect on career commitment. In line with this finding, Allen and Meyer, (2001), showed that tenure is positively related with job position and years of experience to career commitment. The investments and the expectations of individual increase as much as they spend more years within the organization.

However, Sunday, (2011) found in his study of career commitment in Nigeria that there was significant negative relationship between years of experience and career commitment. Also, Aranya, (2003) in his finding stated that years of experience do not have significant influence on career commitment which is in support of this study. This means that the number of years spent in an organization is not an indication of developing commitment. Therefore there are other factors in the organization which may co-vary with years of experience to influence career commitment of workers.

Marital status was found to predict career commitment among health workers. Furthermore, married respondents reported higher level of career commitment than those who were single. Consistent with this result, Bowen, (2004); Dodd-McCue et al, (2006), found that workers who are older and married have more commitment to their organizations and career than the younger and single workers. This may be because, married workers rather than single workers have more family responsibilities to cater for that require financial support and as such they are more committed to the 
organization. Also, Mowdey, (2002) showed that married employees and/or employees with children take their spouse and/or children into consideration when making important decisions, such as changing jobs and the level of their inputs to the organization.

Male health workers were not found to be significantly higher in career commitment than their female counterparts in this study. The result is consistent with that of Shivani et al (2006), who in their separate studies, found no significant relationship between gender and career commitment. This is supported by Adams Stacy (1963) equity theory of motivation which in practical term states that when employees perceive what they get from a job situation (outcomes) in relation to what they put-in (inputs), they compare their outcome-input ratio with the outcome-input ratio of relevant others. If employees perceive the ratio to be equal to that of the relevant others with whom they compare themselves, a state of equity is said to exist; they perceive their situation as fair and that justice prevails which make them more committed to their career. On the other hand, the result contrasted the findings of Geddes et al, (2006), who reported that women were more committed to their career than men. The difference in the outcome of this current study and that of Geddes et al,(2006) could be related to settings of the study and as well as the domain-related differences Hanoch et al, (2006). Geddes et al (2006) based their study on banking and career commitment within the marketing Department while this study was among health workers.

Younger health workers were not found to be significantly higher than their older counterparts on career commitment. This might be as result of the fact that workers are well paid and the necessary incentives are given which facilitates workers to be more committed to their career. This is consistent with the findings of Wiedmer (2006) who found that age was not a significant predictor of job satisfaction and career commitment. However, Dodd-McCue et al, (2006) found that age and job tenure were significant predictors of career commitment. This is probably because, the longer the workers stay with an organization or the older they are, the more time they have to evaluate their relationship and be more committed to their career.

\section{Conclusion and Recommendation}

Career commitment has been found in literature to be associated with organizational outcome. In the health sector, career commitment may have implications for the discharge of health workers' duties. Moreover, commitment to the discharge of their duties has far reaching effect on the clients who depend on the health workers for their health and wellbeing. Therefore, the results of this study have practical implications for health agencies and other organizations in recruitment, placement, training and policy formulation for career path. Firstly the management and policy decision makers in health organizations should recognize the importance of fortitude and emotional intelligence of their workers and the resultant effect on the overall commitment to their career. A conducive and stress reducing environment is required for enhancing workers' career. Again, the study indicated that job status and year of experience had interaction effect on career commitment, thus, organizations should develop a mentoring programme that give room for exchange of ideas between highly experienced workers and younger colleagues. It is also recommended that relevant authorities and policy makers should incorporate these factors into capacity building programmes to enhance workers' commitment to their career.

\section{References}

Adams, J. Stacey (1963), "Toward an understanding of inequity", Journal of Abnormal and Social Psychology, Vol. 67, pp. 422-436.

Allen, N. J., \& Meyer, J.P. (2001). The measurement and antecedents of affective, continuance and normative commitment to the organization. Journal of Occupational Psychology, 63, 1-18.

Alarape, A.I. and Akinlabi F.M.: Influence of Perceived Organizational Support and Discretionary Treatment on Work Attitude of Industrial Workers. African Journal for the Psychological Study of Social Issues, 5(1): 23-36 (2004).

Antonovsky, A. (2002). Health, Stress and Coping. San Fransisco: Josey-Bass.

Antonovsky, A. (2003). Unravelling the Mystery of Health: How People Manage Stress and Stay Well. San Fransico: Josey-Bass.

Aranya, J. G., (2003). Perceived influence of years of experience, task characteristics and job satisfaction on career commitment: A literature review. Academy of management Review, 6: 655-664 Assistants. Journal of College Student Personnel, 23, (4) 320 324.

Bhuain, S. N. and Menguc, B. (2002). An Extension and Evaluation of Job Characteristics, Organizational Commitment, And Job Satisfaction In An Expatriate, Guest Worker, Sales setting", The Journal of Personal Selling and Sales Management, Vol 22 No 1, pp. 1-11.

Blau, G.J. (2003),The measurement and prediction of career commitment, Journal of Occupational Psychology, Vol. 58, pp. $277-88$.

Bohlander, G. and Snell, S. (2007). Managing human resources. South-Western College Publishing, Ohio 
Bowen, C.F., Radhakrishna, R. and Keyser, R ( 2004).: Job satisfaction and commitment of 4-H Agents. Journal of Extension, 32(1): 122. Retrieved $14^{\text {th }}$ July 2006 from http://www.joe.org/joe/19 94jun e/ rb2.html

Brown, C., George-Curran, R., \& Smith, M. (2003). The Role of Emotional Intelligence in the Career Commitment and Decision Making Process Journal of Career Assessment, 11(4), pp. 379-392.

Carmeli, A. (2003). The Relationship between Emotional Intelligence, Attitude, Behaviour and Outcomes. Journal of Managerial Psychology, 18,788-813

Chang, C. S. and Lee, M. S. (2006). Relationships among Personality Traits, Job Characteristics, and Organizational Commitment: An Empirical Study in Taiwan", The Business Review, Cambridge, Vol 6 No 1, pp. 201-207.

Dodd-McCue, D. and Wright, G.B.: Men, women and attitudinal commitment: The effects of workplace experiences and socialization. Human Relations, 49:1065-1089 (2006).

Geddes E., \& Sellaro, C. L. (2006). The Validity of Mobley's 1977 Model of Employee Turnover Organizational Behavior and Human Performance, 34, 141-174.

Goleman D. (2003): Emotional intelligence in the workplace: Exploring its effects on occupational stress and organizational commitment. International Journal of Organizational Analysis, 10(4): 327-342 (2002).

Griffeth, R. W., Hom, P. W., \& Gaertner, S. (2003). A meta-analysis of antecedents and correlates of employee turnover: Update, moderator tests, and research implications for the next millennium. Journal of Management, 26, 463-488

Hackman, J. R, and Oldham, G. R. (1975). New Strategy for Job Enrichment, California management Review, 17(4): 65-75

Hanoch Y., Johnson J. G., Wilke A. (2006). Domain specificity in experimental measures and participant recruitment Psychol. Sci. 17, 300-304. doi: 10.1111/j.1467-9280.2006.01702.X..

Heyns, P.M., Venter, J.H., Esterhuyse, K.G., Bam, R.H. and Odendaal, D.C. (2003). Nurses Caring for Patients with Alzheimer's Disease: Their Strengths and Rise of Burnout. South African Journal of Psychology, 33 (2), 80-85.

Holton, E. F. (2005). New employee development tactics: Perceived availability, helpfulness, and relationship with job attitudes. Journal of Business and Psychology, 16(1), 73-85

Hulin, C.L., Roznowski, M. and Hachiya, D. (2002). Alternative opportunities and withdrawal decisions: Empirical and theoretical discrepancies and an integration. Psychology Bulletin, 97:233-250.

Mor Barak, M. E., Nissly, J. A., \& Levin, A. (2001). Antecedents to retention and turnover among child welfare, social work, and other human service employees: What can we learn from past research? A review and meta-analysis. Social Service Review, 75, 625661.

Mowdey, R. (2000) The measurement of organizational commitment. Journal of Vocational Behaviour, 14: 224-247 .

Mowdey, R.T., Koberg, C.S. and McArthur, A.W. (1984). The Psychology of the Wthdrawal Process: A Cross-Validational Test of Mobley's Intermediate Linkages Model of Turnover in Two Samples. Academy of Management Journal, 27: 79-94.

Pretorius, T.B. (2007). Fortitude as Stress Resistance: Development and Validation of the Fortitude Questionnaire (FORQ). Bellville: University of the Western Cape.Pretorius, T. and Campbell, J. (2004). The Health-Sustaining and Stress-Reducing Roles of Fortitude and the Subjective Experience of Safety in Adolescent's Exposure to Violence in Lower Socio Economic Areas in South Africa

Pretorius, T.B. \& Diedricks, M. (2004). Problem Solving Appraisal, Social Support and the Stress-Depression Relationship. South African Journal of Psychology 24, 86-90.

Salanick, G. \& Pfeffer, J. (2003). A social information processing approach to job and task design. Administrative Science Quarterly, 23: 224-253

Salovey, P. and Mayer, J.D. (2001), 'aEmotional intelligence ${ }^{\circ}$, Imagination, Cognition and Personality, Vol. 9 No. 3, pp. 185-211.

Sanker, C. S. \& Wee, Y. Y. (2005). "Factors Influencing Job Satisfaction of Technical Personnel in the U.S, Singapore, and India", Engineering Management Journal, Vol 9 No 3, pp.15-21.

Schneider, S. E. (2003). Organizational Commitment, Job Satisfaction, and Job Characteristics of Managers: Examining the Relationships across Selected Demographic Variables. Unpublished Doctoral Dissertation, New York University, New York.

Shivani E., Muler T. H., \& Frilled, A. (2006). Workers' Turnover and Commitment in Mexican factories: A Qualitative Investigation and Model Development. Paper presented at the Annual Meetings of the Academy of Management, Cincinnati, $\mathrm{OH}$.

Steel, R.P. \& Griffeth, R.W. (2003). The Elusive Relationship between Perceived Employment Opportunity and Turnover Behavior: A Methodological or Conceptual Artifact. Journal of Applied Psychology, 74(6): 846-854.

Sunday, O., (2011) Career Commitment among Records Management Personnel in a State Civil Service Nigeria. Journal of Career Assessment, 11(4), pp. 379-392.

Wiedmer, S.M.: An Examination of Factors Affecting Employee Satisfaction, (2006). Retrieved 13th July 2006 from http://clearinghouse. missouriwestern edu/manuscripts/51.asp

Wong, C. S., \& Law, K. S. (2002). The Effects of Leader and Follower Emotional Intelligence on the Performance and Attitude: An Exploratory Study. The Leadership quarterly, 13, 234-247.

Yagil, D. (2002). "Substitution of a Leader's Power bases by Contextual Variables", International Journal of Organizational Theory and Behavior, Vol 5 No 3, pp. 383-399. 